\title{
手性膦腈碱有机催化的研究进展
}

\author{
张艳霞 $a, b$ 韩建伟*, $, a, b$ \\ ( ${ }^{a}$ 华东理工大学化学与分子工程学院精细化工系 上海市功能性材料化学重点实验室 上海 200237) \\ ${ }^{b}$ 中国科学院上海有机化学研究所 沪港化学合成联合实验室 上海 200032)
}

\begin{abstract}
摘要 有机碱催化不对称合成是小分子催化化学的重要分支, 也是手性合成领域的研究热点之一. 膦腈碱化合物是有 机超强碱, 性质稳定，可作为一类有机强碱小分子催化剂应用于不对称催化有机反应. 讨论了膦腈碱化合物在小分子 催化领域的研究进展, 包括膦腈碱的合成以及其在不对称反应中的应用.

关键词 手性膦腈碱; 不对称; 研究进展; 有机催化
\end{abstract}

\section{Recent Progress of Chiral Iminophosphorane Catalysis}

\author{
Zhang, Yanxia ${ }^{a, b} \quad$ Han, Jianwei ${ }^{*, a, b}$ \\ ( ${ }^{a}$ Shanghai Key Laboratory of Functional Materials Chemistry, Department of Fine Chemicals, School of Chemistry \& Mo- \\ lecular Engineering, East China University of Science and Technology, Shanghai 200237) \\ ( ${ }^{b}$ Shanghai-Hong Kong Joint Laboratory in Chemical Synthesis, Shanghai Institute of Organic Chemistry, \\ Chinese Academy of Sciences, Shanghai 200032)
}

\begin{abstract}
As organocatalysts, organic base catalysts play an important role in the quest for optically pure compounds. Chiral iminophosphoranes, being organosuperbases, are very stable under air and moisture conditions, thereby providing an attractive platform for the design of various asymmetric organocatalysts. The recent achievements concerning chiral iminophosphoranes in the development of both organocatalysis and their applications in asymmetric synthesis are summarized and discussed.

Keywords chiral iminophosphorane; asymmetric catalysis; research progress; organocatalysis
\end{abstract}

不对称催化化学是一个快速发展的研究领域. 金属 催化、酶催化和有机催化是获取立体多样性的最主要的 三条途径. 尤其是不对称有机催化, 以小分子作为催化 剂诱导各种不对称反应得到了广泛的关注. 2000 年 List $^{[1]}$ 和 MacMillan ${ }^{[2]}$ 等分别报道了手性胺催化不对称反 应，随即开启了有机催化的复兴时代. 目前各种各样的 有机催化剂、反应模式及其关联的反应类型被陆续开发 出来, 为不对称合成提供了崭新的平台. 其实, 有机碱 小分子催化可以追溯到 1912 年, Bredig 和 Fiske ${ }^{[3]}$ 使用金 鸡纳碱作为小分子催化剂催化不对称反应, 尽管取得的 立体选择性较低, 但是该反应奠定了手性 Brønsted 碱作 为催化剂诱导不对称反应发生的基础.

1985 年, Schwesinger ${ }^{[4]}$ 介绍了一类不带电荷的含氮 有机膦腈碱、三个氨基和一个膦亚氨基团取代的五价磷
结构, 以磷为中心树枝状发散而构建的含多个磷单元的 膦腈. 根据磷的个数可称为 $\mathrm{P} n$ 碱 $^{[5-6]}$, 随着 $n$ 数增加, 其 碱性呈现越来越强的趋势(图 1). 该化合物对水和空气 不敏感，易溶于有机溶剂，因此得到大量的应用并成为 人名试剂. 该类碱所表现出的强碱性可能是由正电荷在 分子内共轭体系中得到分散而引起的 ${ }^{[7-8]}$. 而膦腈碱在 有机溶剂中的良好溶解度和稳定性, 主要得益于其较大 的空间位阻而不易被亲核试剂进攻和水解 ${ }^{[9-11]}$. 2009 年, Ishikawa $^{[12]}$ 对超强碱进行了定义, 指出碱性与 1,8 -双二 甲氨基萗(DMAN, $\mathrm{p}{K_{\mathrm{BH}}}^{+}=18.62$ )相当或者大于 DMAN 的非离子型有机分子均称之为超强碱. 因此, 具有膦腈 结构的化合物又称膦腈超强碱.

1994 年, Allen ${ }^{[9]}$ 将含有膦亚胺结构的五价膦衍生物 统称为膦腈. 随后，化学家们制备了不同的手性膦腈化

\footnotetext{
* Corresponding author. E-mail: jianweihan@ecust.edu.cn

Received May 18, 2020; revised June 19, 2020; published online June 30, 2020.

Dedicated to Professor Henry N. C. Wong on the occasion of his 70th birthday.

Project supported by the National Natural Science Foundation of China (Nos. 21472213, 21202186) and the Croucher Foundation of Hong Kong. 国家自然科学基金(Nos. 21472213, 21202186)和香港装槎基金资助项目.
} 
<smiles>CN(C)P(N)(=NC(C)(C)C)N(C)C</smiles>

(26.98)<smiles>CCN(CC)P1(=N)N(C)CCCN1C(C)(C)C</smiles>

(27.63)

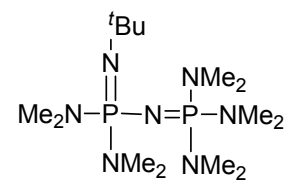

(33.49)
P3<smiles>CN(C)P(C)(=O)N=P(N)(N=P(N(C)C)(N(C)C)N(C)C)N(C)C</smiles>

(38.6)

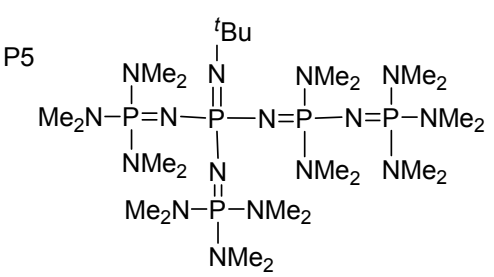

(45.3)
图 1 膦腈碱 $\mathbf{P 1} \sim \mathbf{P 5}$ 的结构(括号内为乙腈中的 $\mathrm{p} K_{\mathrm{BH}+}$ 值) Figure 1 Structures of phosphazene bases $\mathbf{P 1} \sim \mathbf{P 5}\left(\mathrm{p} K_{\mathrm{BH}+}\right.$ values in $\mathrm{CH}_{3} \mathrm{CN}$ are given in parenthesis)

合物并将其应用到有机合成中. 手性膦腈碱类化合物根 据不同结构类型可以分为三大类(图 2). 类型一是五价 磷上通过 $\mathrm{P}-\mathrm{N}$ 单键连接三个有位阻的手性胺基团, 它 们的 $\mathrm{p}{K_{\mathrm{BH}}}^{+}$大约在 35 37 之间. 类型二是螺环型手性膦 腈碱，或者是去质子化原位生成的螺环膦腈碱. 类型三 是一种双官能团膦腈碱，具有强碱性膦亚胺基团的同
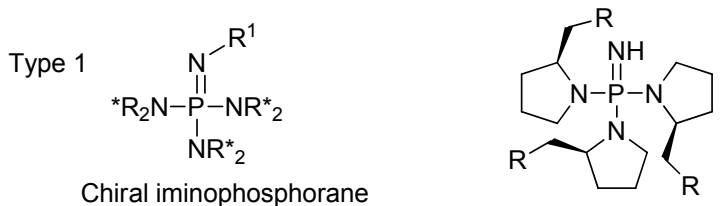

Chiral iminophosphorane
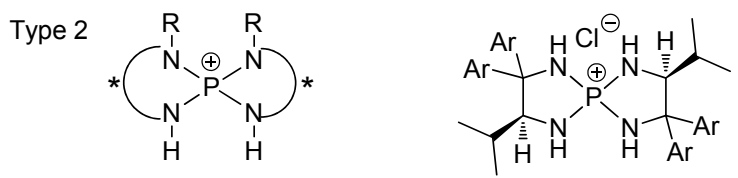

Chiral spiro-iminophosphorane precursor
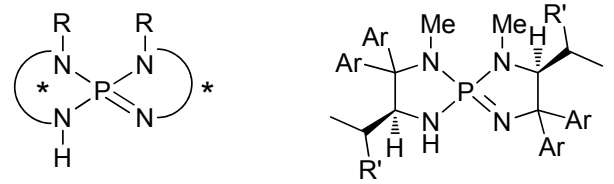

Chiral spiro-iminophosphorane

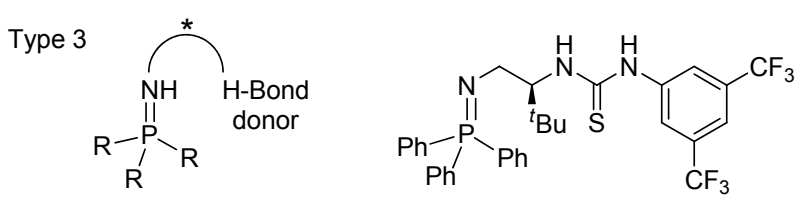

Bifunctional systems

图 2 手性膦腈碱的类型

Figure 2 Types of chiral iminophosphoranes
时，还带有能提供氢键作用的分子结构而构成双功能催 化剂. 这一类型的催化剂在反应过程中可以分别活化亲 核试剂和亲电试剂. 并通过催化剂骨架拉近两个反应物 的距离, 从而提高反应转化率和选择性 ${ }^{[13]}$. 近年来, 手 性膦腈化合物在不对称合成中作为有机碱催化剂出现 了许多报道, 本文针对手性膦腈结构的催化剂, 按照化 学结构进行了分类, 总结了其在不对称催化中的研究成 果.

\section{1 含有膦亚胺单元的手性膦腈化合物}

2008 年, Kondo 和 Naka 课题组 ${ }^{[14]}$ 报道了基于手性 二苯乙二胺的双膦亚胺单元的新膦腈化合物与锂离子 形成的复合催化剂, 实现了查尔酮与丙二酸酯化合物的 不对称 Michael 加成反应，以优秀收率和最高 $89 \% e e$ 的 对映选择性得到最终产物(Eq. 1).

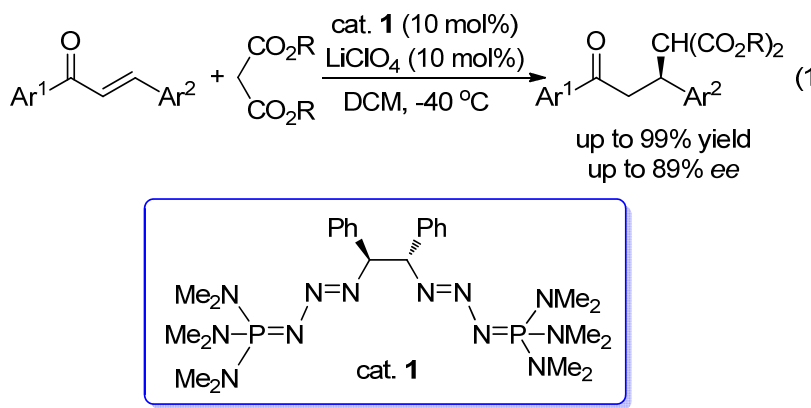

2006 年, Anders 小组 ${ }^{[13]}$ 报道了含有 $(S)$-吡咯烷结构 的 P1 膦腈碱化合物的合成, 然而并没有报道其应用. 2014 年, Sundermeyer 小组 ${ }^{[15]}$ 合成了手性联菜骨架的含 有双 P2 单元的膦腈超强碱(Eq. 2), 并得到了相关的单 晶数据. 其可与对甲苯磺酸或者六甲基二铝成盐, 然而 并没有对其催化应用进行研究.

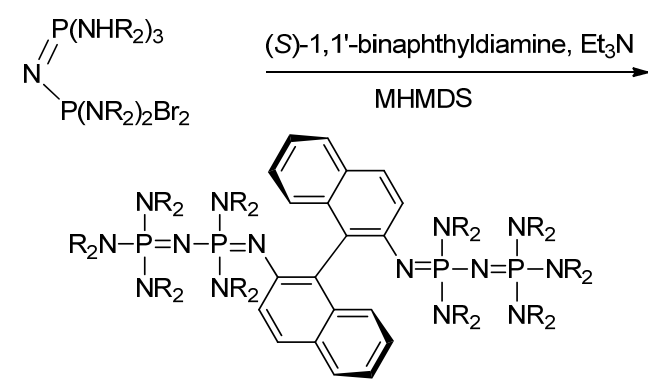

$\mathrm{NR}_{2}=\mathrm{NMe}_{2}(28 \%$ yield $), \mathrm{N}\left(\mathrm{CH}_{2}\right)_{4}(55 \%$ yield $)$

\section{2 手性膦腈碱催化剂应用于不对称反应}

2.1 Ooi 小组合成的手性螺环膦腈碱在不对称反应中 的应用

具有 $[5,5]-$ 膦螺环的膦腈碱，是具有刚性骨架的有 机碱化合物. 2007 年, Ooi 小组 ${ }^{[16]}$ 首次设计并合成了相 
关的以磷为中心的四氨基季鏻盐, 并报道了其在不对称 催化反应方面的研究. 作者以简单易得的 $L$-纾氨酸为原 料, 首先合成了手性 1,2 二二胺化合物, 之后二胺与 $\mathrm{PCl}_{5}$ 在三乙胺作为缚酸剂的条件下, 一步生成五元螺环鏻 盐. 得到的鏻盐往往是一对异构体而需要进一步分离纯 化(Scheme 1).

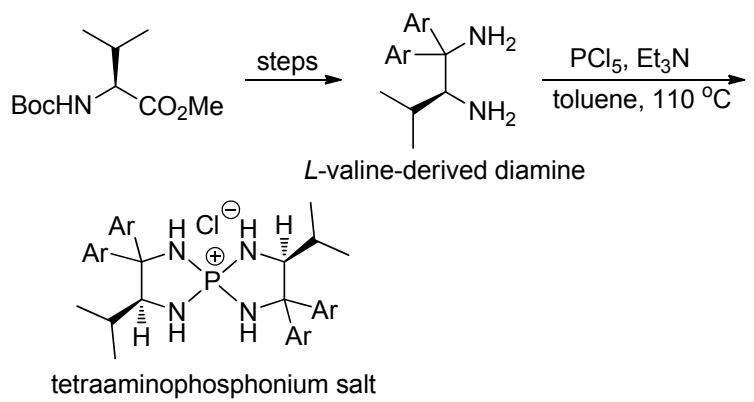

图式 1 螺环催化剂的合成

Scheme 1 Synthesis of spiro-catalysts

此后, Ooi 小组 ${ }^{[16,18-32,34-46]}$ 通过类似的策略, 基于手 性氨基酸、手性联菜二胺和手性二苯乙二胺等成熟的二 胺合成子开发了一系列的手性螺环鏻盐 $(2 \sim 5$, 图 3), 并 将其作为膦腈碱催化剂的前体用于各种各样的不对称 化学反应中, 取得了丰硕的成果.

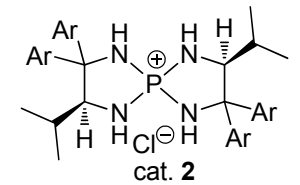

2a, $\mathrm{Ar}=4-\mathrm{CF}_{3} \mathrm{C}_{6} \mathrm{H}_{4}$ 2b, $\mathrm{Ar}=4-\mathrm{CH}_{3} \mathrm{C}_{6} \mathrm{H}_{4}$ 2c, $\mathrm{Ar}=4-\mathrm{FC}_{6} \mathrm{H}_{4}$

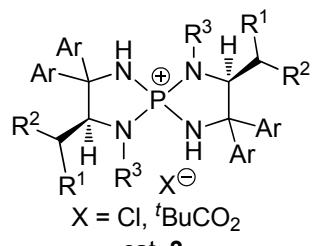
cat. 3

3a, $\mathrm{R}^{1}=\mathrm{R}^{2}=\mathrm{R}^{3}=\mathrm{Me}, \mathrm{Ar}=4-\mathrm{ClC}_{6} \mathrm{H}_{4} \mathrm{X}=\mathrm{Cl} ; \mathrm{Ph}^{\prime \prime \prime}$ 3b, $R^{1}=R^{2}=R^{3}=M e, A r=P h$; 3c, $R^{1}=M e, R^{2}=E t, R^{3}=M e, A r=P h ;$

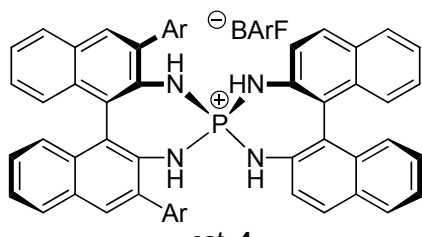

cat. 4

4a, $\mathrm{Ar}=3,4,5-\mathrm{F}_{3} \mathrm{C}_{6} \mathrm{H}_{2}$ $\mathrm{BArF}=\left(3,5-\left(\mathrm{CF}_{3}\right)_{2} \mathrm{C}_{6} \mathrm{H}_{3}\right)_{4} \mathrm{~B}$

4b, $\mathrm{Ar}=4-\mathrm{CF}_{3}-2-\mathrm{PhC}_{6} \mathrm{H}_{3}$ BArF $=\left(3,5-\left(\mathrm{CF}_{3}\right)_{2} \mathrm{C}_{6} \mathrm{H}_{3}\right)_{4} \mathrm{~B}$

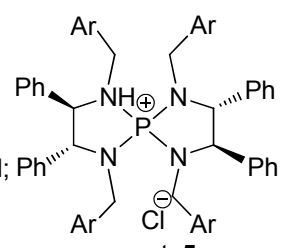
cat. 5

3d, $R^{1}=R^{2}=R^{3}=\mathrm{Me}, \mathrm{Ar}=\mathrm{Ph}, \mathrm{X}={ }^{t} \mathrm{BuCO}_{2} ; \mathrm{Ar}=3,5-\left({ }^{t} \mathrm{BuMeSi}\right)_{2} \mathrm{C}_{6} \mathrm{H}_{3}$ 3e, $\mathrm{R}^{1}=\mathrm{H}, \mathrm{R}^{2}={ }^{i} \mathrm{Pr}, \mathrm{R}^{3}=\mathrm{Me}, \mathrm{Ar}=4-\mathrm{FC}_{6} \mathrm{H}_{4}$; 3f, $\mathrm{R}^{1}=\mathrm{H}, \mathrm{R}^{2}=\mathrm{Pr}, \mathrm{R}^{3}=\mathrm{Me}, \mathrm{Ar}=3-\mathrm{MeC}_{6} \mathrm{H}_{4}$;

3g, $R^{1}=M e, R^{2}=E t, R^{3}=M e, A r=P h ;$

3h, $R^{1}=\mathrm{Me}, \mathrm{R}^{2}=\mathrm{Et}, \mathrm{R}^{3}=\mathrm{Et} \mathrm{Ar}=\mathrm{Ph}$;

3i, $\mathrm{R}^{1}=\mathrm{Me}, \mathrm{R}^{2}=\mathrm{Et}, \mathrm{R}^{3}=\mathrm{Me}, \mathrm{Ar}=3,5-\mathrm{Cl}_{2} \mathrm{C}_{6} \mathrm{H}_{3}$;

3j, $\mathrm{R}^{1}=\mathrm{Me}, \mathrm{R}^{2}=\mathrm{Et}, \mathrm{R}^{3}=\mathrm{Me}, \mathrm{Ar}=3-\mathrm{FC}_{6} \mathrm{H}_{4}$;

3k, $\mathrm{R}^{1}=\mathrm{R}^{2}=-\left(\mathrm{CH}_{2}\right)_{5^{-}}, \mathrm{R}^{3}=\mathrm{Me}, \mathrm{Ar}=4-\mathrm{FC}_{6} \mathrm{H}_{4}$

图 3 Ooi 小组发展的手性催化剂

Figure 3 Chiral catalysts by Ooi group

2007 年, Ooi 小组 ${ }^{[16]}$ 首先将五元螺环鏻盐 $\mathbf{2 a}$ 作为催 化剂前体应用于硝基烷烃与醛的不对称 Henry 反应. 在
强碱叔丁醇钾的存在条件下，鏻盐生成相应的膦腈碱活 化硝基烷烃，成功实现了硝基烷烃与芳香醛或者脂肪醛 加成反应. 以高的非对映选择性(4：1１9：1 anti/syn) 以及优秀的对映选择性(93\% 99\% ee)生成 $\beta$-硝基醇化 合物(Eq. 3).

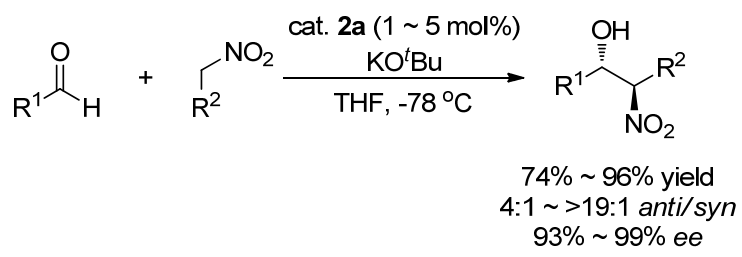

对于反应机理作者提出下面的假设(Scheme 2): 鏻 盐在叔丁醇钾作用下去质子形成膦亚胺，硝基烷烃去质 子与膦亚胺通过双氢键作用生成中间体，具有手性环境 的硝基负离子与醛反应生成立体选择性的硝基醇产物, 而膦亚胺再生并进入下一次的循环中. 2015 年, Paton 等 ${ }^{[17]}$ 通过计算化学的手段给出了催化模型的最佳中间 态，也验证了 Ooi 小组推测的机理.
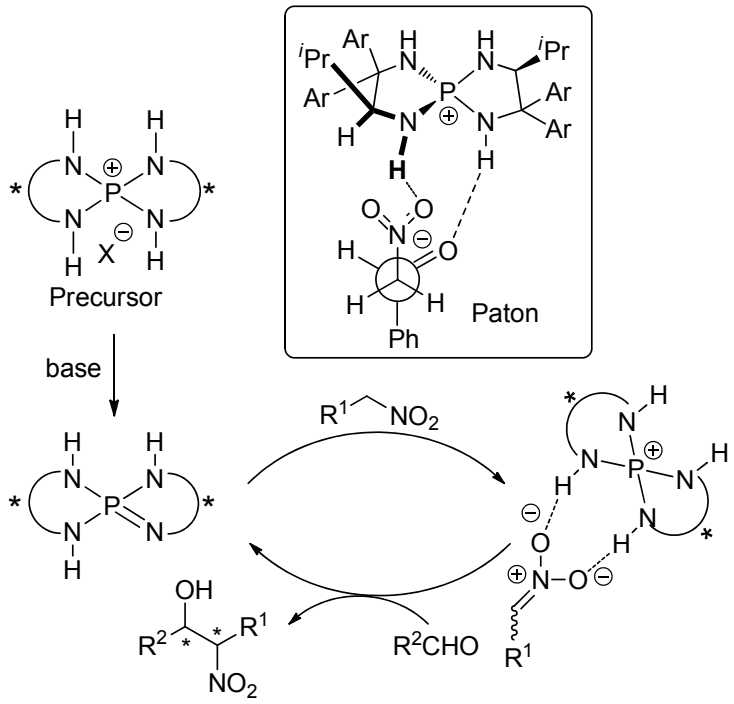

图式 2 Henry 反应的催化机理

Scheme 2 Catalytic mechanism of Henry reaction

2009 年, Ooi 小组 ${ }^{[18]}$ 进一步拓展了膦腈碱催化剂. 使用 3a 催化硝基化合物与丙酮酸酯的不对称 Henry 反 应，以中等到优秀的收率(50\% 98\%)和优秀的立体选 择性(6：1～10：1 $d r, 72 \% \sim 92 \% e e$ )得到加成产物(Eq. 4). 此外，在有机合成反应类型方面也进行了进一步的 拓展. 2010 年该小组 ${ }^{[19]}$ 报道使用膦腈碱 $2 \mathbf{b}$ 催化硝基化 合物对炔基醛的不对称 Henry 反应. 用叔丁醇钾作碱、 在一 $78{ }^{\circ} \mathrm{C}$ 的反应条件下，四氢呋喃( THF) $/ N, N$-二甲基 甲酰胺(DMF)为反应溶剂，高收率 $(88 \% \sim 99 \%)$ 和高立 体选择性(10：1～20：1 $d r, 88 \% \sim 99 \%$ ee)地生成了 anti- $\beta$-硝基炔醇. 


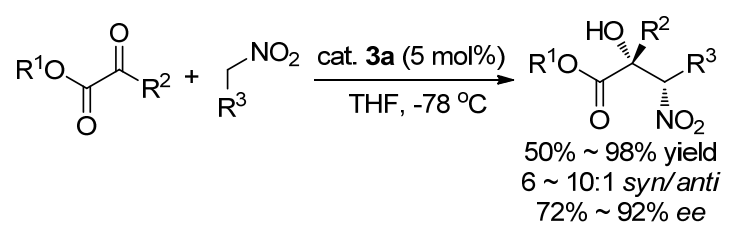

Ooi 小组又报道了 $\alpha$-差基膦酸酯的不对称合成. 催 化剂鏻盐在叔丁醇钾作用下生成的膦腈碱, 可以与亚磷 酸酯相互作用形成离子对, 该离子对通过了 $-98{ }^{\circ} \mathrm{C}$ 的 ${ }^{31} \mathrm{P}$ 谱图的验证. 手性膦腈碱形成的离子对以磷负离子 的形式对醛的 $\alpha$ 位进行不对称羟基化. 该反应使用 1 $\mathrm{mol} \%$ 的催化剂量、在 $-98{ }^{\circ} \mathrm{C}$ 的温度下, 以 $\mathrm{THF}$ 作为溶 剂, 芳基和直链脂肪基取代的醛均高效率和高选择性地 生成相应的 $\alpha$-差基膦酸酯产物(Eq. 5) ${ }^{[20-21]}$. 相同的反应 方法亦可对炔基邻位上的羰基进行 $\alpha$-羟基膦酸酯化, 制 备具有立体中心的产物 ${ }^{[22]}$. 此外, 膦腈碱 $3 \mathbf{b}$ 催化 $\alpha$-差弪 基膦酸酯对醛的直接不对称 Aldol 加成反应，产物又经 过膦酸酯重排迁移得到 $\alpha$-羟基- $\beta$-膦酸酯化合物(Eq. $6)^{[23]}$.

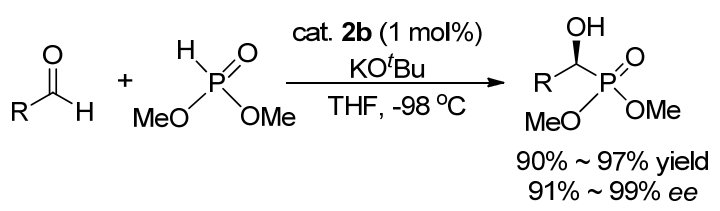

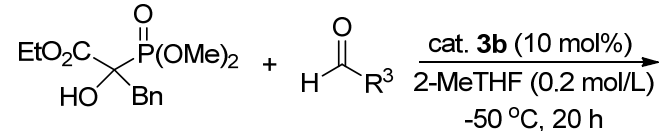

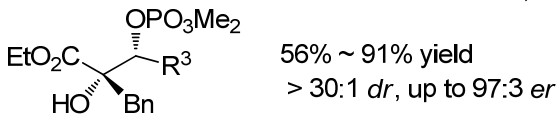

2012 年, Ooi 小组 ${ }^{[24]}$ 报道了在混合溶剂 THF/DMF 中, 3c 来催化鲐内酯化合物对硝基烯烃的不对称 Michael 加成反应, 以高收率(82\% 99\%)和高立体选择 (up to $20: 1 d r, 91 \% \sim 98 \% e e$ ) 得到加成产物. 呋内酯化 合物是一类有用的合成子(Eq. 7). 在催化鲐内酯化合物 方面, 膦腈碱也可以与其他分子通过氢键形成手性集结 体而催化不对称反应. Ooi 小组 ${ }^{[25-26]}$ 报道了 $\mathbf{3 c}$ 与三分子 酚通过氢键作用自组装形成手性超分子. 该超分子作为 催化剂催化唤酯化合物与 $\alpha, \beta$-不饱和酯的不对称加成 反应，以 $90 \% \sim 98 \%$ 的收率、 $\geqslant 20: 1$ 的非对映选择性 以及 $93 \% \sim 98 \%$ 的对映选择性得到产物(Eq. 8).

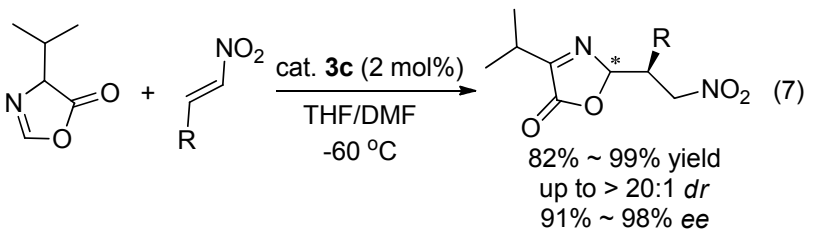

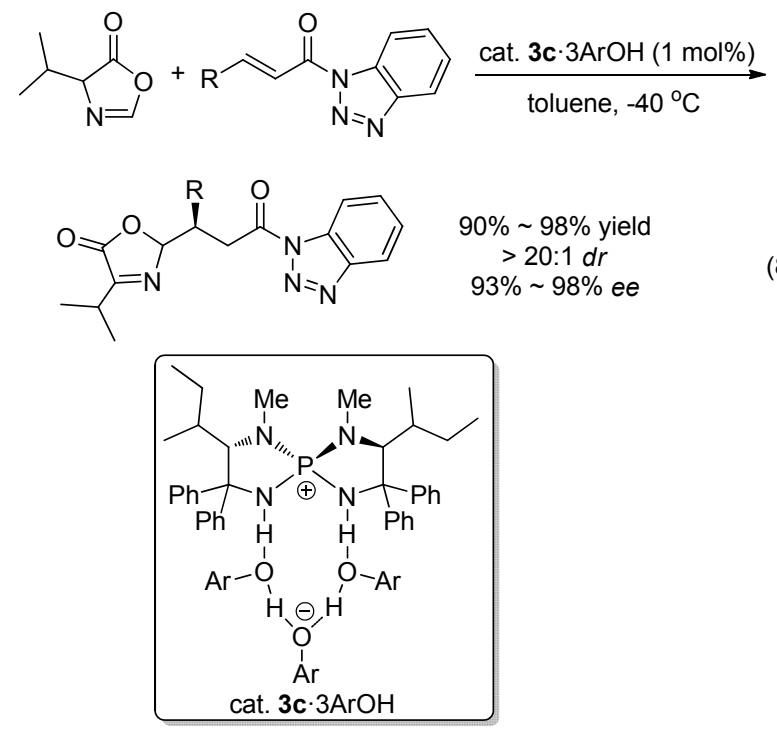

为了进一步探究五元螺环膦腈碱化合物在不对称 反应中的应用, Ooi 小组利用 3 催化浐内酯化合物与双 键的不对称加成反应. 2008 年, Ooi 等 ${ }^{[27]}$ 报道了 3d 催化 唤内酯化合物与亚胺的 Mannich 反应，以 $88 \% \sim 99 \%$ 的 收率、 $2.3: 1 \sim 12: 1$ 的非对映选择性及 $90 \% \sim 97 \% \mathrm{ee}$ 的对映选择性得到加成产物(Scheme 3). 2012 年，他们 ${ }^{[28]}$ 报道了唤酯化合物与二、三烯酰基吡咯的高立体选 择性的加成反应(Scheme 3). 2017 年, Ooi 小组 ${ }^{[29]}$ 还报道 了唤内酯化合物与联烯酰胺通过 1,6-加成得到加成产 物，在反应中使用不同的反应条件下可以生成构型不同 的产物，产物具有优秀的收率(80\% 96\%)和对映选择 性( $>95 \% e e)$. 并且通过计算化学的方法验证反应的机 理, 给出了最优的反应过渡态 ${ }^{[30]}$. 此外, 膦腈碱 $\mathbf{3 e}$ 催化 唤内酯化合物与烯酮的反应，以不错的收率 $(64 \%$ 99\%)和优秀的立体选择性(>15：1dr, 90\% 99\% ee)得 到了目标产物 ${ }^{[31]}$.

2013 年, Ooi 小组 ${ }^{[32]}$ 探究了膦腈碱 $2 \mathbf{a}, 3 \mathbf{c}$ 分别催化 唤内酯化合物对吸电子端炔的 Michael 加成反应, 在反 应中可得到不同构型的产物. Paton 等 ${ }^{[33]}$ 在 2017 年使用 Gaussian ONIOM (QM/MM)方法对其机理进行了研究, 得到了与实验一致的结果，催化剂的结构影响加成反应

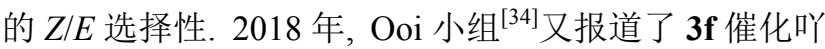
内酯与 $N$-烯炔酰基吡咯的 Michael 反应. 当鲐内酯与端 炔反应时，在乙醚作为溶剂条件下，可以高区域选择性 地得到加成产物; 在非端炔条件下，用甲基叔丁基醚 (TBME)作为溶剂, 也实现了高收率、高立体选择性的加 成反应(Scheme 3). 膦腈碱 $\mathbf{3 g}$ 也可实现含硫内酯化合物 与非末端炔烃的不对称加成反应, 以甲苯为溶剂、 $0{ }^{\circ} \mathrm{C}$ 条件下，以 $71 \% \sim 95 \%$ 的收率、9 > $20: 1 E / Z$ 和 $95 \% \sim 99 \%$ ee 的对映选择性得到加成产物 ${ }^{[35]}$. 


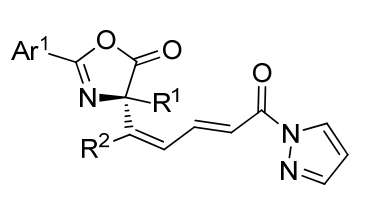

$84 \% \sim>95 \%$ site-selectivity $88 \% \sim 99 \%$ yield $90 \% \sim 98 \%$ ee

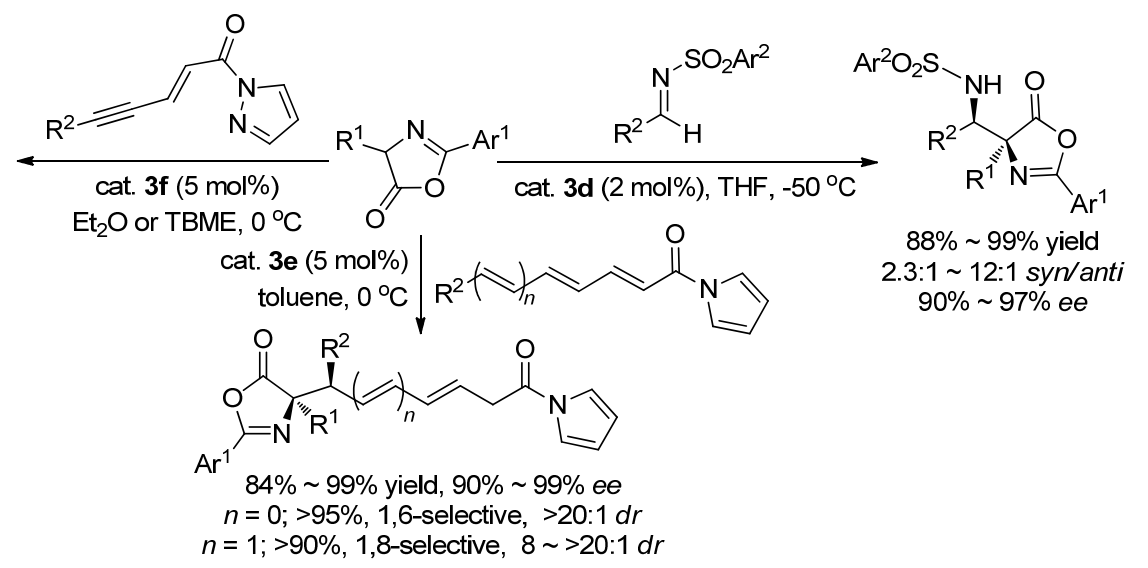

图式 3 监内酯化合物的不对称加成反应

Scheme 3 Enantioselective addations of azlactones
2014 年, Ooi 等 ${ }^{[36]}$ 接着报道了膦腈碱 $3 \mathbf{h}$ 催化烯基砜 与硝基烷烃的不对称 Michael 加成反应, 取得了优秀的 收率(80\% 97\%)和对映选择性(80\% 97\% ee) (Scheme 4). 2018 年, 该小组 ${ }^{[37]}$ 以 $3 c$ 为催化剂, 高收率 $(61 \%$ $99 \%)$ 、高非对映选择性(>20：1E/Z)以及高对映选择性 (92\% 98\% ee) 地实现了 $\alpha$-氨基酸衍生物与联烯的 Michael 加成反应(Scheme 4). 该反应过渡态的理论研究 以及控制实验证明了动态动力学起决定性作用.

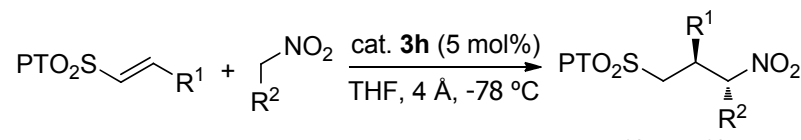

$$
\begin{aligned}
& 83 \% \sim 99 \% \text { yield } \\
& 12: 1 \sim>20: 1 d r
\end{aligned}
$$

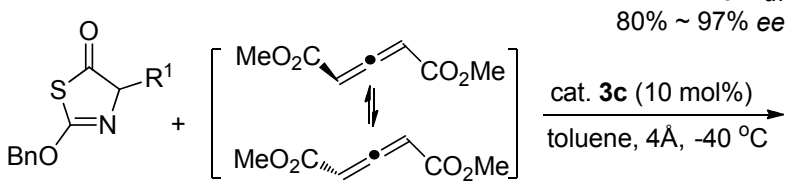

$$
\begin{aligned}
& \begin{array}{c}
62 \% \sim 99 \% \text { yield } \\
>20: 1 \mathrm{E} / \mathrm{Z} \\
92 \% \sim 98 \% \text { ee }
\end{array}
\end{aligned}
$$

图式 4 不对称 Michael 反应

Scheme 4 Asymmetric Michael reactions

此外, Ooi 小组 ${ }^{[38]}$ 研究了 $N$-磺酰基亚胺与双氧水在 $3 \mathbf{i}$ 作用下的不对称环氧化反应. 使用芳环上含有吸电子 的催化剂, 环氧化产物的收率达 99\%, 对映选择性达 98\% ee (Eq. 9). 2017 年又报道了催化剂 3j 催化的 $N$-磺酰 基亚胺酯与双氧水的不对称环氧化反应 ${ }^{[39]}$.

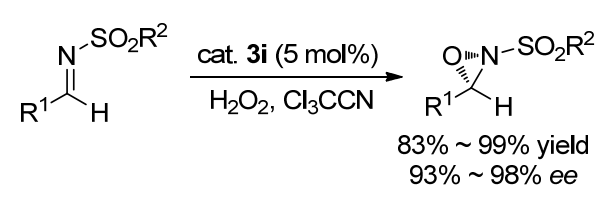

2015 年, Johnson 小组和 Ooi 小组 ${ }^{[40]}$ 合作报道了膦 腈碱 $3 \mathbf{b}$ 催化靛红和醛之间的不对称多组分还原偶联反 应. 该反应需要化学计量的亚磷酸二乙酯作为还原剂, 碱催化 Pudovik 加成反应, 然后膦酸酯重排而致使靛红 发生极性反转而进攻醛基, 接着发生磷酰基迁移. 该反 应具有优秀的收率和优秀的对映选择性(Scheme 5).

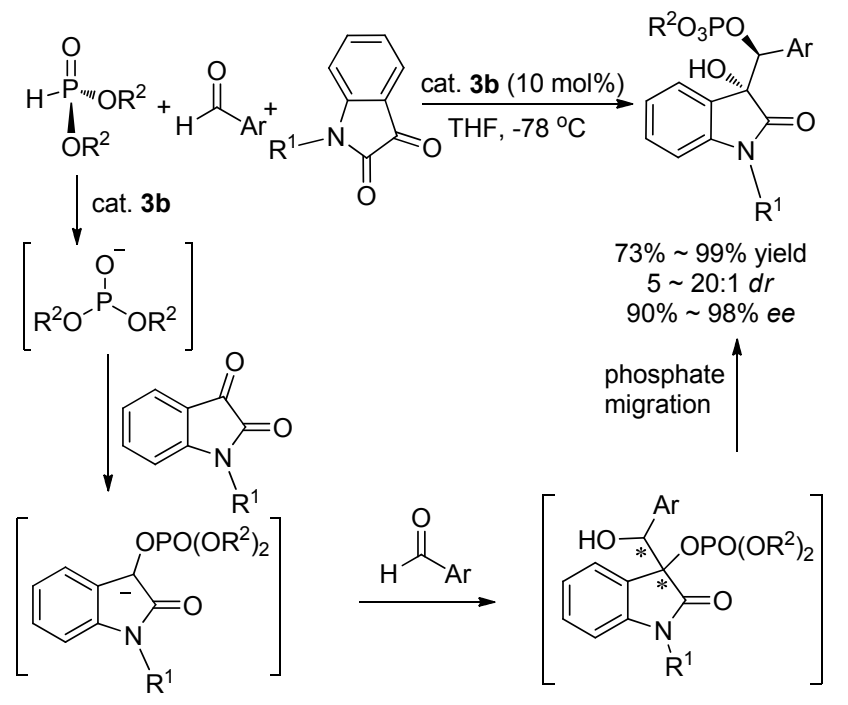

图式 5 青定红与醛之间的不对称还原多组分偶联反应

Scheme 5 Enantioselective reductive multicomponent coupling reactions

2018 年, Ooi 小组 ${ }^{[41]}$ 使用膦腈碱 $\mathbf{3 k}$ 催化硫化物与醛 的不对称 Aldol 反应，以高收率(up to 98\%)、高非对映选 择性(>20：1 $d r$ ) 以及高对映选择性(up to $97 \% e e$ )得到 目标产物. 硫化物去质子化致使酰基发生迁移，通过分 子内动态平衡, 中间体再与醛发生加成反应生成目标化 合物(Scheme 6).

除了手性氨基酸衍生的螺环催化剂, Ooi 课题组 ${ }^{[42]}$ 还发展了新型联菜骨架的膦腈碱 $\mathbf{4}$, 并将其应用于不对 称有机催化. 如, $\mathbf{4 a}$ 催化硝基烯烃与芳基胺的不对称 


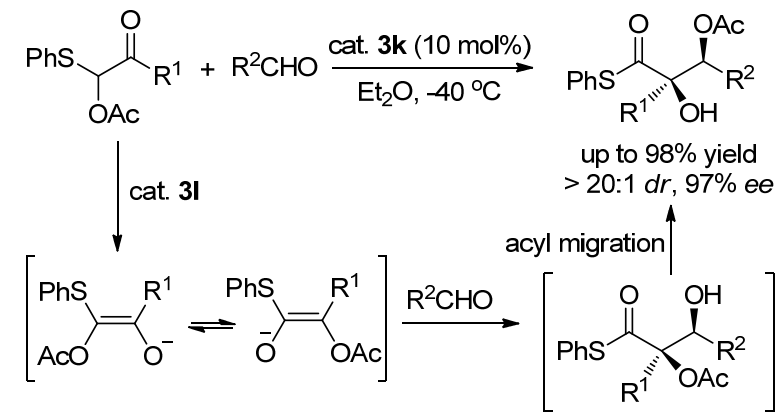

图式 $6 \alpha$-乙酰氧基- $\beta$-羊炭基硫化物的缩合反应

Scheme 6 Deprotonating $\alpha$-acetoxy- $\beta$-ketosulfide for aldolization

加成反应, 在 $2 \mathrm{~mol} \%$ 的催化剂用量下以优秀的收率 $(89 \% \sim 99 \%)$ 以及对映选择性( $86 \%$ \% $7 \%$ ee) 得到产物 (Eq. 10). 膦腈碱 $\mathbf{4 a}$ 还可以通过手性离子对 Brønsted 酸非手性 Brønsted 碱协同催化实现硝基烯烃与硫酚的加 成反应，得到优秀的收率(97\% 99\%) 和对映选择性 ${ }^{[43]}(90 \% \sim 97 \% e e)$. 此外, $4 \mathbf{b}$ 与光敏剂实现协同光催化, 在可见光条件下, $\mathbf{4 b}$ 催化磺酰亚胺与 $N$-芳基甲胺的不对 称氧化还原 $\alpha$-偶联反应, 得到了中等到优秀的收率 (60\% 90\%) 以及优秀的对映选择性(85\% 98\% ee) (Eq. $11)^{[44]}$. 之后, 作者 ${ }^{[45]}$ 还报道了 $4 \mathbf{b}$ 催化含有硅基保护的 甲胺与磺酰亚胺之间的不对称偶联反应, 该反应取得中 等到优秀的收率 $(28 \% \sim 86 \%)$ 以及优秀的对映选择性 $(78 \% \sim 97 \% e e)$.

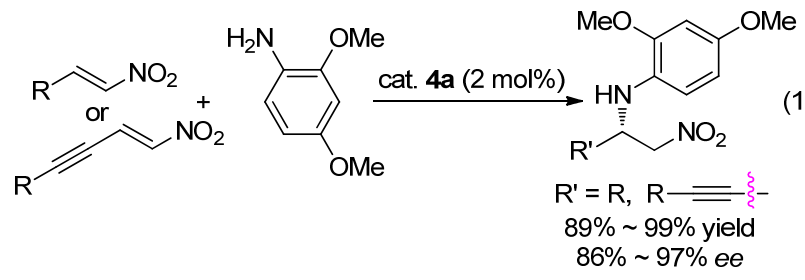

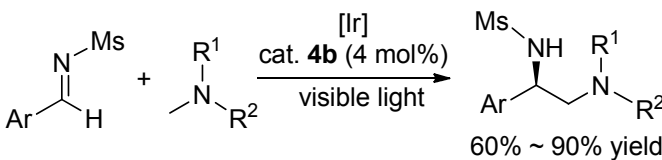

$$
\begin{aligned}
& 85 \% \sim 98 \% \text { ee }
\end{aligned}
$$

2009 年, Ooi 等 ${ }^{[46]}$ 设计合成了基于手性二苯基乙二 胺骨架的新催化剂 5 . 膦腈碱 5 以高收率(up to 98\%)和 高非对映选择性(up to $99: 1 d r$ ) 催化了多肽衍生的鲐内 酯化合物对烷基卤代烃的不对称烷基化反应(Eq. 12). 该方法可以用于在肽链特定位置插入手性氨基酸单元.<smiles>[R]C1N=C(C([R])NC(=O)OCc2ccccc2)OC1=O</smiles>

2.2 Terada 小组合成的手性螺环膦腈碱在不对称反应 中的应用

2013 年, Terada 小组 ${ }^{[47]}$ 合成了一种新的含有两个胍 基团的光学纯的 [7,7]- $P$-螺环鏻盐 6 . 利用手性二苯基乙 二胺作为原料, 先通过三步反应将其中一个氨基转变成 为胍基而得到相应的关键中间体，然后在碱性条件下与 $\mathrm{PCl}_{5}$ 反应，关环得到具有螺环结构含有两个胍基的鏻 盐. 然而生成的盐是一对异构体, 通过柱层析分离可得 到单一构型的产物. 其中 $M$ 构型的鏻盐由于两个 $\mathrm{N}$ 上的 $\mathrm{H}$ 同时朝向一边, 显示出了优秀的催化效果(Scheme 7).

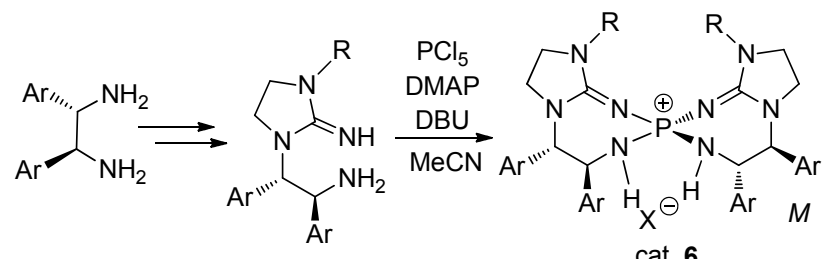

6a, $\mathrm{R}=\mathrm{Me}, \mathrm{X}=\mathrm{Br}, \mathrm{Ar}=\mathrm{Ph} ; \mathbf{6 b}, \mathrm{R}={ }^{t} \mathrm{Bu}, \mathrm{X}=\mathrm{Cl}, \mathrm{Ar}=\mathrm{Ph}$

6c, $\mathrm{R}=\mathrm{CHPh}_{2}, \mathrm{X}=\mathrm{Cl}, \mathrm{Ar}=\mathrm{Ph} ; \mathbf{6 d}, \mathrm{R}=\mathrm{Bn}, \mathrm{X}=\mathrm{Cl}, \mathrm{Ar}=\mathrm{Ph}$

6e, $\mathrm{R}={ }^{t} \mathrm{Bu}, \mathrm{X}=\mathrm{Cl}, \mathrm{Ar}=1$-naphthyl

图式 7 螺环膦腈碱前体的合成

Scheme 7 Synthesis of iminophosphoranes

在得到新结构催化剂的基础上, Terada 等 ${ }^{[47]}$ 以 $\mathbf{6 a}$ 作 为催化剂前体在强碱 $\mathrm{NaN}\left(\mathrm{SiMe}_{3}\right)_{2}$ 作用下, 生成膦腈碱 催化剂, 在甲苯中可以高收率(up to 99\%)和高对映选择 性(up to $98 \% \mathrm{ee}$ )地催化苯并环状酮衍生物的 $\alpha$-位不对 称胺化反应(Eq. 13).

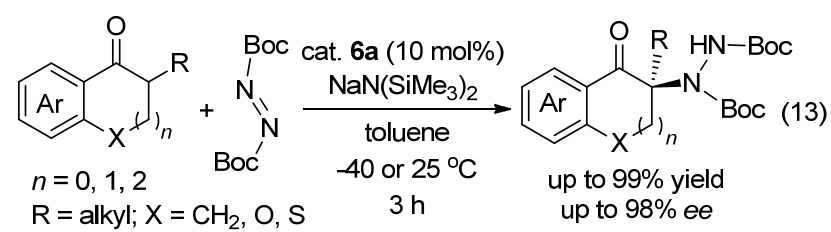

此后, Terada 小组 ${ }^{[48]}$ 利用螺环膦腈碱前体 6 催化了 亚胺与各种各样底物的 Mannich 反应, 立体选择性生成 相应的旋光纯的胺类化合物，该产物可以作为手性合成 子应用于各种旋光碱的合成(Scheme 8). 膦腈碱 $\mathbf{6 a}$ 生成 的强碱催化剂能够脱去 2-茮基吡定 $N$-氧化物茮位的质 子而生成碳负离子，从而与亚胺发生加成反应，以中等 到优秀的立体选择性高效得到手性目标化合物(Scheme 8). 之后, 该小组 ${ }^{[49]}$ 继续使用膦腈碱前体 $\mathbf{6 b}$ 与强碱一起 催化 $N$-Boc 亚胺与 1,3-二噻烷-2-甲酸茮酯的不对称加成 反应，依然以高收率(88\% 99\%)和高对映选择性(99\% $e e$ )得到相应的手性胺产物(Scheme 8). 此外, 膦腈碱前 体 $\mathbf{6 c}$ 生成的碱催化剂促进 $\gamma$-硫羰内酯对亚胺基化合物 的不对称加成反应, 高收率(up to $99 \%$ )和高立体选择性 (95：5９9：1 $d r, 83 \% \sim 95 \% e e$ )地构建具有邻双季碳 
手性中心的 $\alpha$-氨基酸衍生物 ${ }^{[50]}$ (Scheme 8). 综上所述, 螺环膦腈碱前体 6 可以生成具有催化作用的超强碱物 种，并且具有非常优秀的立体控制效果.

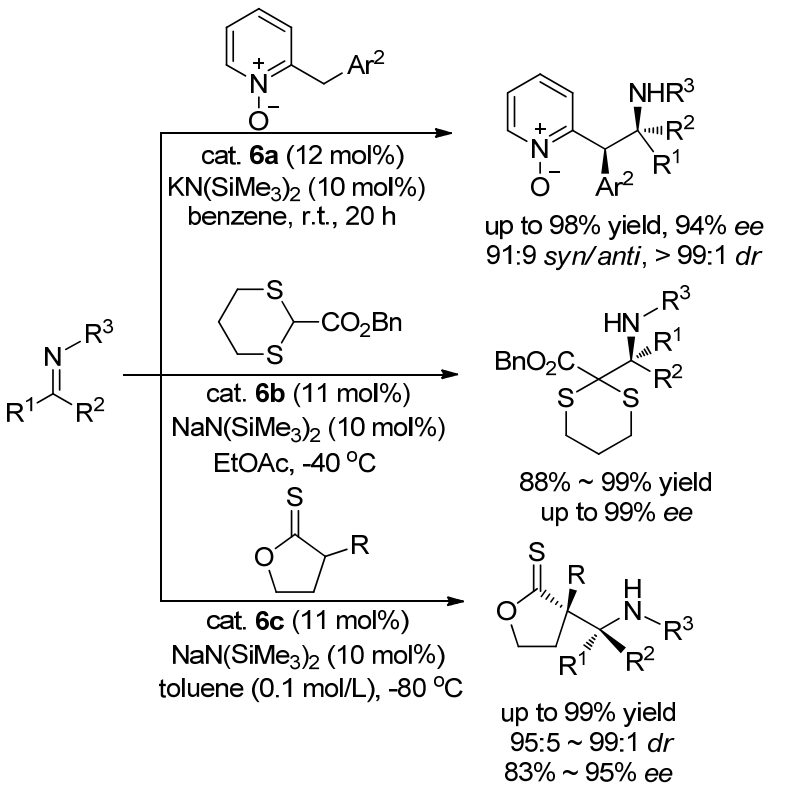

图式 8 亚胺化合物的不对称 Mannich 型反应

Scheme 8 Diastereo- and enantioselective Mannich-type reactions of imines

2018 年, Terada 小组 ${ }^{[51]}$ 又报道荎基取代的[7,7]螺环 膦腈碱化合物 $6 \mathrm{e}$, 其可以促进磺酰基 $\alpha$ 位去质子生成磺 酰基稳定的 $\alpha$-碳负离子, 然后重排成烯丙氧负离子中间 体，该中间体对亚胺进行亲核加成，进而发生氨基负离 子对烯基砜的分子内 aza-Michael 加成得到形式 [3+ 2]环化反应, 以高达 $99 \%$ 的收率和最高可达 $93 \%$ ee 的对 映选择性生成五元杂环化合物(Eq. 14).

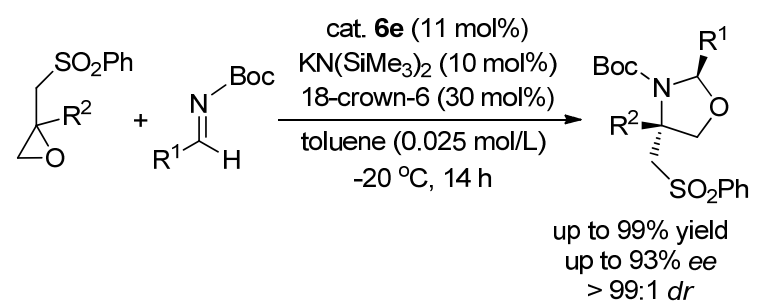

\section{$2.3 \mathrm{Han}$ 小组合成的手性螺环膦腈碱在不对称反应中 的应用}

自 2011 年伊始, 本课题组也致力于手性膦腈碱催 化剂的设计、制备及其在不对称反应的应用研究. 2015 年, 以 $L$-酒石酸为起始原料成功合成了手性七元螺环膦 腈碱催化剂 ${ }^{[52]}$. $L$-酒石酸经过三步可以合成 $(4 R, 5 R)-$ $\alpha, \alpha, \alpha^{\prime}, \alpha^{\prime}$ - 四芳基 - 2,2'-二甲基 - 二氧戊环 - 4,5 -二甲醇 (TADDOL), 之后再经过重氮化、还原合成手性二胺, 最 后在三乙胺作为缚酸剂的条件下与 $\mathrm{PCl}_{5}$ 反应, 制备手性
膦腈碱 7. 由于该膦腈碱的对称性, 故不存在异构体. 而且含有四个二芳基亚甲基砌块，从而稳定了膦亚胺化 合物. 因此该膦腈碱性质稳定，对空气及湿度不敏感， 从而具有可以室温长期储存的优点. 无论催化剂前体还 是膦腈碱的结构都通过单晶测试进行了确认(Scheme 9).

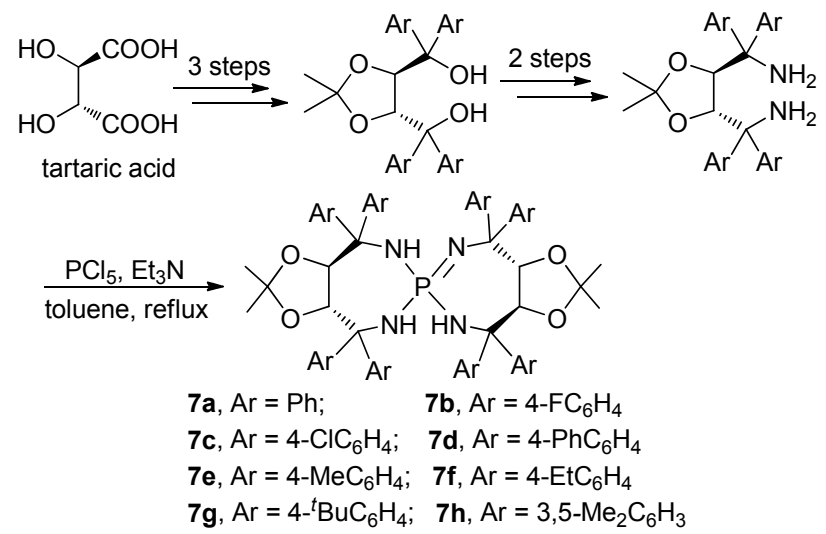

图式 9 催化剂 7 的合成

Scheme 9 Synthesis of catalysts 7

在此基础上, 膦腈碱 7 作为小分子催化剂被用于多 个不对称单元反应中. 膦腈碱 $7 \mathbf{g}$ 可催化吲哚酮化合物 的不对称氯化反应，以高收率(93\% 99\%)及高对映选择 性(90\% 99\% ee)得到相应的氯化产物(Scheme 10). 值 得指出的是，该催化剂可以重复循环使用，收率以及对 映选择性都能够得到很好地保持，在不对称氯化反应 中，反应放大到克级反应，几乎定量地得到旋光纯的氯 化产物. 而且对催化剂进行了 6 次回收, 并将回收的催 化剂应用于不对称氯化反应，催化剂的活性和选择性没 有丝毫的降低，这证明了催化剂的稳定性和良好的催化 活性. 接下来, 膦腈碱 $\mathbf{7 g}$ 也可以催化吲哚酮化合物与多 聚甲醛的不对称羟甲基化反应，以优秀的收率 $(81 \%$ $98 \%$ )以及中等到优秀的对映选择性(30\% 94\% ee) 得到 羟甲基化产物 ${ }^{[53]}$ (Scheme 10). 最近，我们小组 ${ }^{[54]}$ 还使用 催化剂 $7 \mathrm{~g}$ 不对称催化了吲哚酮化合物的苯硒基化反应, 对映选择性最高可达 97\% ee (Scheme 10). 上述反应均可 实现放大而不降低反应效率和反应对映选择性，并且实 现催化剂的回收循环使用.

2018 年, 我们小组 ${ }^{[55]}$ 又以氧氮杂环丙烷作为羟基 化试剂, 在膦腈碱 7d 催化下实现了吲哚酮化合物的不 对称羟基化反应，取得了优秀的收率(91\%～99\%)和不 错的对映选择性(up to $94 \% e e$ ). 在 3-苯基取代的吲哚酮 的反应中, 7d 表现出了最优异的催化效果; 而在 3-茮基 取代的吲哚酮中，催化剂 7e 表现最优(Scheme 11). 此 外, 在 7e 催化下实现吲哚酮化合物与 $(N$-苯硫基)邻苯二 甲酰亚胺的反应，以高收率( $90 \% \sim 99 \%)$ 以及中等到优 秀的对映选择性(up to $90 \% e e$ )生成苯硫基化的产物， 


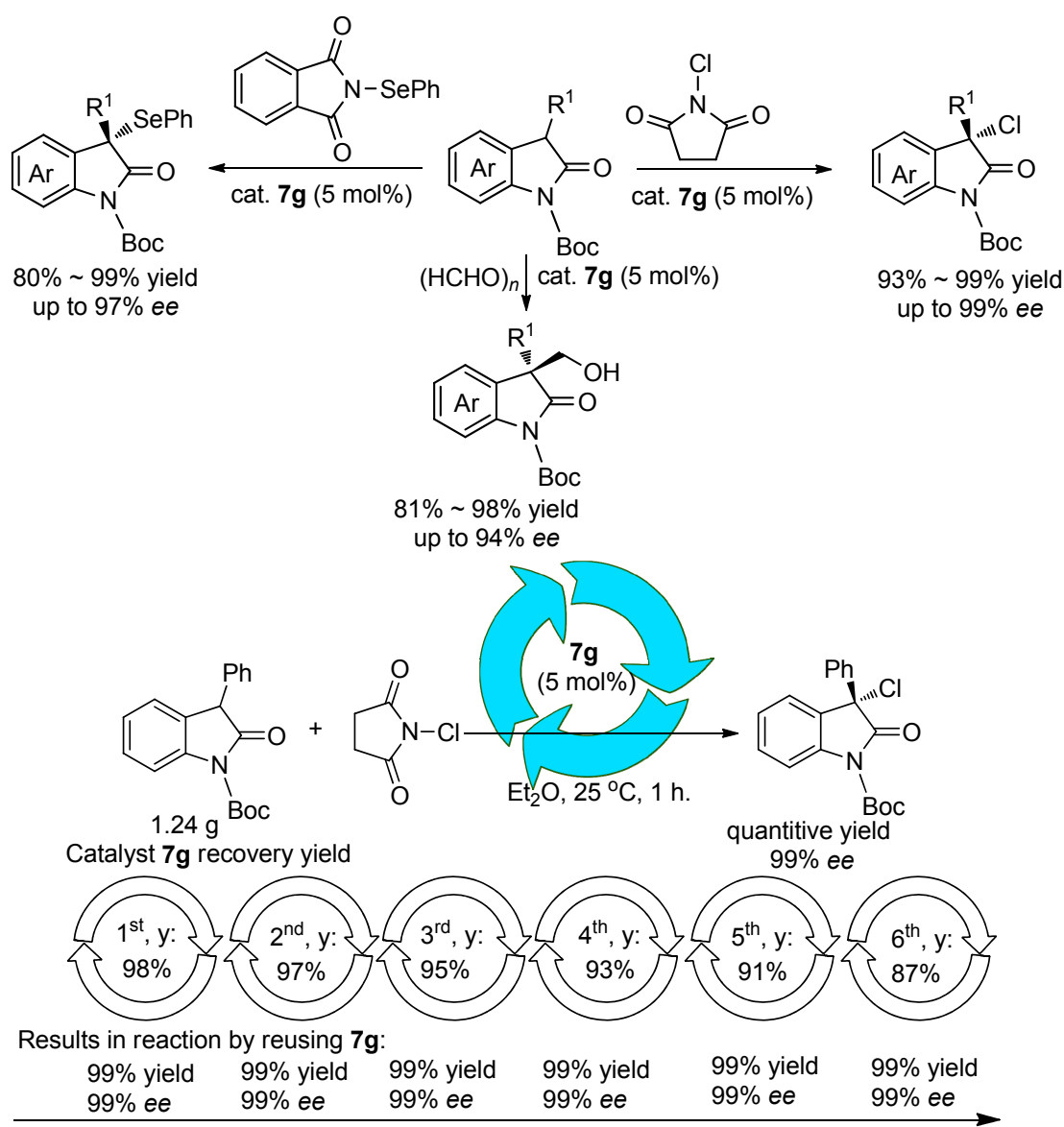

图式 10 手性膦腈碱催化吲哚酮化合物的不对称羟甲基化, 氯化, 苯硒基化反应; 以及催化剂在不对称氯化反应中的循环使用 Scheme 10 Chiral iminophosphorane catalyzed asymmetric hydroxymethylation/chlorination/phenylselenylation of oxindoles, and recyclable use of catalyst in asymmetric chlorination of oxindoles

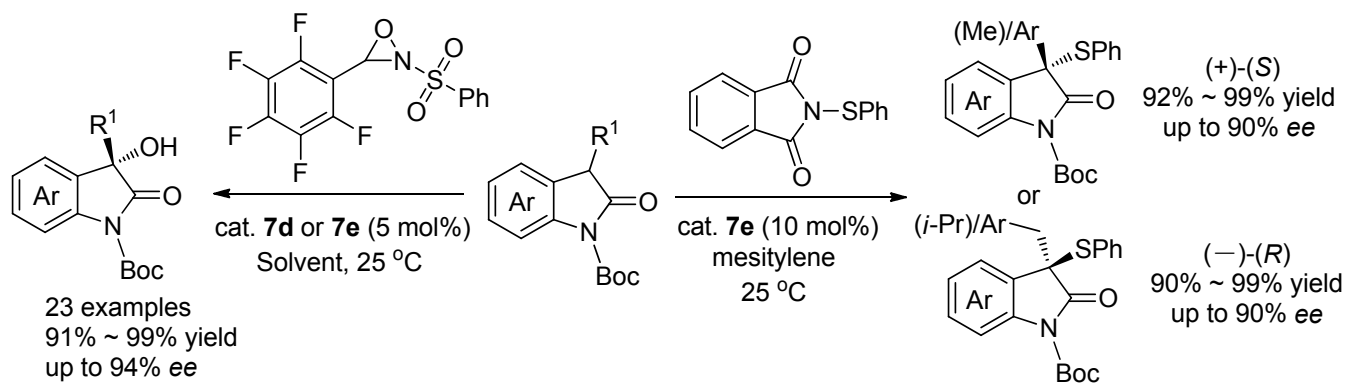

图式 11 手性膦腈碱催化吲哚酮化合物的不对称羟基化以及巯基化反应

Scheme 11 Chiral iminophosphorane catalyzed asymmetric hydroxylation and sulfenylation of oxindoles

吲哚酮的 $\mathrm{C}(3)$ 位可以是芳基或者烷基取代，C(3)位上取 代基不同, 得到产物的构型也不相同 ${ }^{[56]}$ (Scheme 11), 底物上取代基与最终产物的绝对构型密切相关.

除了吲哚酮衍生物, 对催化剂适用的反应底物也做 了进一步拓展. 在膦腈碱 $\mathbf{7 g}$ 的催化下, 实现了 4-取代吡 咯啉酮化合物的不对称苯硫基化反应, 以优秀的收率 (80\% 99\%)以及优秀的对映选择性(up to $99 \%$ ee) 得到 了不对称苯硫基化产物. 反应中以非极性溶剂正己烷为 溶剂, 正己烷对反应底物只能部分溶解而催化剂则完全 溶解, 有效提高了均相中催化剂对反应底物的比例. 反
应过程中底物不断的溶解，从而形成了一个虚拟的连续 进料均相反应器(Scheme 12, a). 而且该反应的底物适用 范围广, 产物分离方法简单 ${ }^{[57]}$. 同样的策略还实现了膦 腈碱 $7 \mathbf{g}$ 不对称催化链状氰基乙酸酯化合物的苯硫基化反 应，对映选择性最高达 $88 \% e e^{[58]}($ Scheme $12, \mathrm{~b})$.

最近, 我们 ${ }^{[59]}$ 报道了螺环膦腈碱化合物 $7 \mathbf{g}$ 催化硝 基烷烃与炔基取代酮酸酯的不对称 Henry 反应. 在 20 $\mathrm{mol} \%$ 的催化剂量下，炔基酮酸酯与硝基甲烷反应，以 最高 $87 \%$ ee 的对映选择性生成了相应的手性炔醇化合 物(Scheme 12, c). 

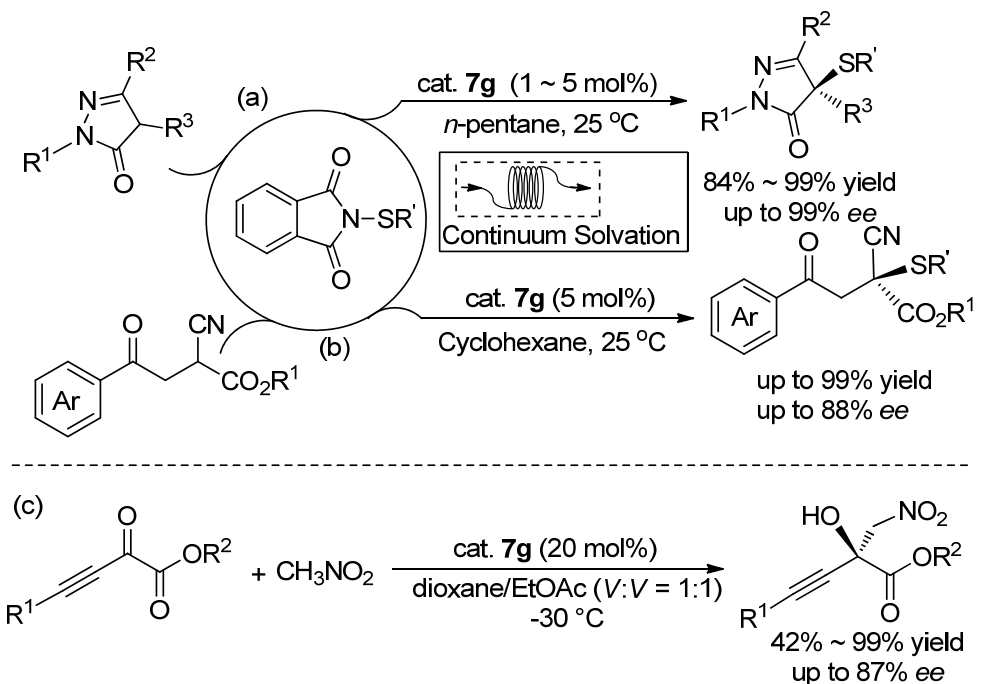

图式 12 手性膦腈碱催化不对称放基化和 Henry 反应

Scheme 12 Chiral iminophosphorane catalyzed asymmetric sulfenylations and Henry reactions

\section{4 双功能团的手性膦腈碱催化剂在不对称反应中的 应用}

2013 年, Dixon 小组 ${ }^{[60]}$ 报道了具有双功能团的膦腈 碱 8, 又称之为 BIMP 催化剂(Scheme 13). 催化剂中既 含有膦亚胺单元进行碱基活化, 同时又含有硫艮单元发 生氢键活化作用. 该催化剂由叠氮化合物与三苯基膦作 用一步就可以得到. Dixon 小组 ${ }^{[61]}$ 对该催化剂进行了固 载, 由聚苯乙烯基三苯基膦和叠氮化合物反应制备得到 手性膦腈碱 9 (Scheme 13).
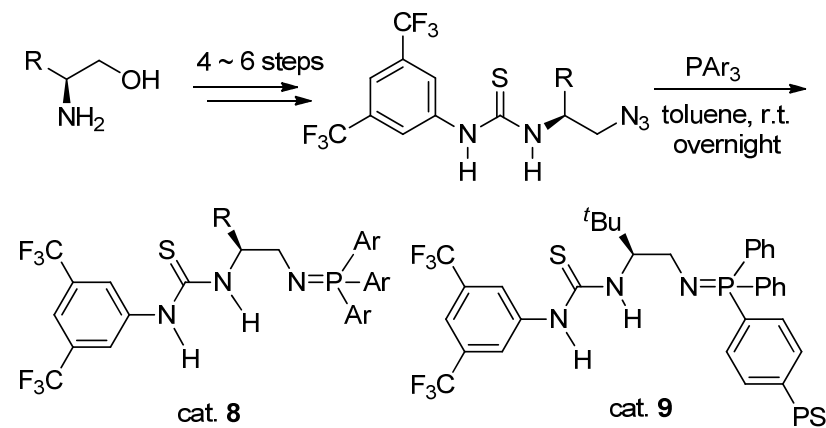

8a \& 8f $\mathrm{R}={ }^{t} \mathrm{Bu} ; \mathbf{8 b}, \mathrm{R}={ }^{i} \mathrm{Pr}$

$8 \mathrm{c}, \mathrm{R}=\mathrm{CHPh}_{2} ; \mathbf{8 d}, \mathrm{R}=\mathrm{Bn} ; \mathbf{8 e}, \mathrm{R}=\mathrm{Ph}$

PS = Polymer Supported

$8 \mathbf{a} \sim \mathbf{8 e}, \mathrm{Ar}=\mathrm{Ph} ; \mathbf{8 f}, \mathrm{Ar}=\mathrm{PMP}$

图式 13 合成双功能膦腈碱化合物

Scheme 13 Synthesis of bifunctional iminophosphoranes

双功能团型膦腈碱 8a 和 9 催化了硝基甲烷与亚胺 的 aza-Henry 反应(Eq. 15). 其中膦亚胺单元可以通过去 质子化活化硝基烷烃，同时硫艮的氢键作用活化了亚胺 化合物，从而反应生成一系列硝基取代的手性胺. 催化 剂 8a 在该反应表现了优秀的产率以及对映选择性(产率 40\% 97\%, 78\% 95\% ee). 同样地, 使用固载的膦腈碱
9 也能获得优秀的结果(产率 $71 \% \sim 96 \%, 86 \% \sim 96 \% e e$ ), 在反应中 9 通过过滤即可回收，催化循环多次，其活性 基本没有变化.

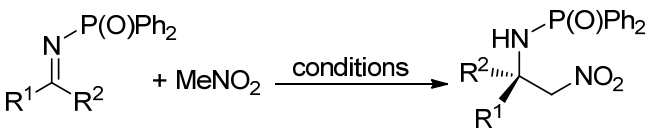

condition A: cat. 8a (10 mol\%), $-15 \sim 0{ }^{\circ} \mathrm{C}, 20 \sim 96 \mathrm{~h}$, $40 \% \sim 97 \%$ yield, $78 \% \sim 95 \%$ ee

condition B: cat. 9 (10 mol\%), PhMe, $0{ }^{\circ} \mathrm{C}, 72 \mathrm{~h}$, $71 \% \sim 96 \%$ yield; $86 \% \sim 96 \%$ ee

2016 年, Dixon 等 ${ }^{[62]}$ 实现了 8f 催化的 phosphaMannich 型反应. 在 $10 \mathrm{~mol} \%$ 的 $8 f$ 作用下，亚胺可与亚 磷酸二乙酯发生 Mannich 型反应. 该反应条件温和, 收 率高达 99\%，对映选择性最高可达 71\% ee (Scheme 14, a). 同年, Johnson 小组 ${ }^{[63]}$ 利用双功能膦腈碱 $8 \mathbf{a}$ 催化了丙 酮酸酯化合物和醛的不对称还原偶联反应 (Scheme 14, b). 接着该小组还报道了双功能膦腈碱 $8 \mathrm{e}^{\prime}$ ( $\mathrm{R}$ 苯基的绝 对构型与 $8 \mathrm{e}$ 相反)催化硝基乙烷或者硝基丙烷与烯酮化 合物的 Michael 加成反应，取得了非常优秀的非对映选 择性(>20：1 $d r)$ 和对映选择性(93\% 99\% ee, Scheme $14, \mathrm{c})^{[64]}$.

2015 年, Dixon 小组 ${ }^{[65]}$ 重新构造了 BIMP 双官能膦 腈碱 $10 \sim 12$. 引进了手性环已二胺砌块合成了 11; 将 3,5-二三氟甲基取代的芳基改成一个酰胺保护的氨基酸 单元，以增加多个有功能的官能团以提高立体控制作 用，合成了 12(图 4 ).

12c 可用于丙烯酸酯与硫醇的 sulfa-Michael 加成反 应. Brønsted 碱用于活化硫醇，而硫脲基团通过氢键作 用活化丙烯酸酯，该反应条件温和，实验操作简单，以 高达 99\%的收率和 $96 \%$ ee 的对映选择性得到目标化合 
(a)

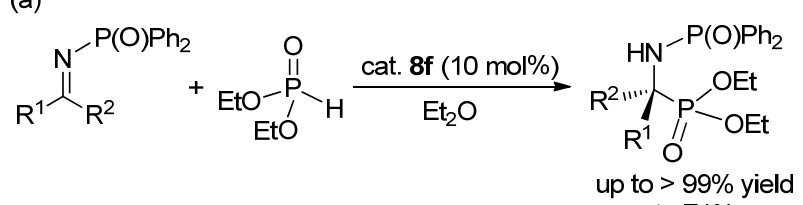$$
\text { up to } 71 \% \text { ee }
$$

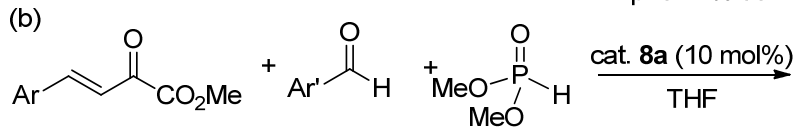$$
\text { Ar } \mathrm{APO}_{3} \mathrm{Me}_{2}
$$

$43 \% \sim 84 \%$ yield

up to $16: 1 d r$, up to $95 \%$ ee

$$
\text { (c) }
$$$$
>20: 1 d r \text {, up to } 99 \% \text { ee }
$$

图式 14 不对称加成反应

Scheme 14 Enantioselective addition reactions

$$
\begin{aligned}
& \mathrm{EWG}=\mathrm{Ts} \\
& \mathrm{EWG}=\mathrm{C}(\mathrm{O}) \mathrm{NH}\left(m, m-\mathrm{CF}_{3}\right)_{2} \mathrm{C}_{6} \mathrm{H}_{3} \\
& \mathrm{EWG}=\mathrm{C}(\mathrm{O})\left(m, m-\mathrm{CF}_{3}\right)_{2} \mathrm{C}_{6} \mathrm{H}_{3}
\end{aligned}
$$

$$
\text { cat. } 10
$$

cat. 12 12a, $R^{1}=\mathrm{H}, \mathrm{R}^{2}={ }^{t} \mathrm{Bu}, \mathrm{R}^{3}={ }^{t} \mathrm{Bu}, \mathrm{R}^{4}=\mathrm{Me}$

12b, $R^{1}=H, R^{2}={ }^{t} B u, R^{3}={ }^{t} B u, R^{4}=H$

12c, $R^{1}=P h, R^{2}={ }^{t} B u, R^{3}={ }^{t} B u, R^{4}=H$

12d, $R^{1}=P h, R^{2}=P h, R^{3}={ }^{t} B u, R^{4}=H$

图 4 修饰的双功能膦腈碱催化剂

Figure 4 Modified bifunctional iminophosphoranes

物 ${ }^{[65]}\left(\right.$ Scheme 15). 2017 年, Dixon 小组 ${ }^{[66]}$ 使用 12d' $\left(\mathrm{R}^{3}\right.$ 叔丁基的绝对构型与 $\mathbf{1 2 d}$ 相反)催化硫醇化合物与 $\alpha, \beta-$ 不饱和酯的共轭加成反应, 以最高 $98 \%$ 的收率以及 $94 \%$ $e e$ 的对映选择性得到硫杂 Michael 加成产物(Scheme 15). 2018 年, 该小组 ${ }^{[67]}$ 又报道以 12c'作为催化剂 $\left(\mathrm{R}^{3}\right.$ 叔 丁基的绝对构型与 $\mathbf{1 2 c}$ 相反), 催化硫醇与烯基取代苯丙 咪唑化合物的 Michael 加成反应, 最高具有 $98 \%$ 的收率 以及 $92 \% e e$ 的对映选择性(Scheme 15).

2020 年, Dixon 小组 ${ }^{[68]}$ 对含多功能团催化剂做了进 一步修改, 合成了以酰胺作为氢键供体的膦腈碱 13. 该 催化剂由叠氮化合物和三苯基膦一步反应得到, 而手性

$$
\text { cat. 12c (10 mol\%) }
$$

图式 15 硫 Michael 加成反应

Scheme 15 Sulfa-Michael additions

叠氮化合物可由 1,2-氨基醇经过 9 步反应得到. 双官能 团膦腈碱 13 催化甲基芳基酮与 $\alpha$-三氟甲基芳基酮的交 叉 Aldol 反应，得到了相应的手性叔醇化合物(Eq. 16). 在反应中该催化剂可以加速烯醇中间体的生成, 从而促 进 Aldol 反应顺利进行，具有高达 $98 \%$ ee 的对映选择性.

$$
\text { }
$$

2020 年, Terada 小组 ${ }^{[69]}$ 报道了含有胍基以及 P2-膦 腈碱结构单元的膦腈超强碱 14, 并将其应用于相对不 活泼底物 $\alpha$-苯硫基乙酸酯化合物的不对称 Mannich 反 应. 在一个膦腈碱分子中含有两个不同的有机碱官能 才，在两个官能团的共同协作下，以高达 $95 \%$ ee 的对映 选择性得到含有苯硫基和氨基双手性中心的目标化合 物(Eq. 17).

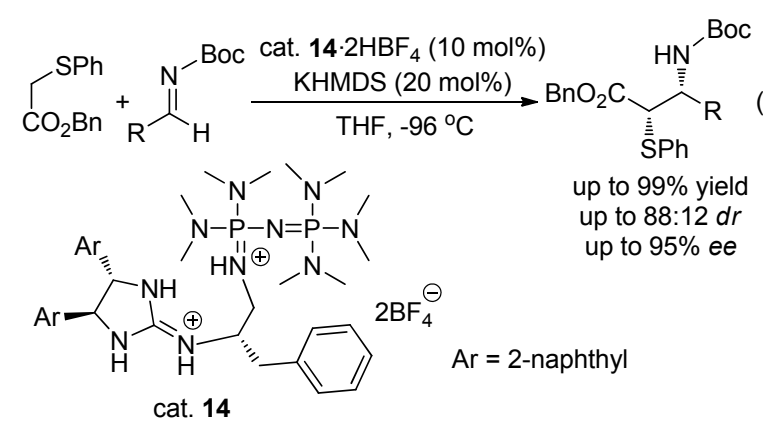




\section{3 结论与展望}

主要总结了手性膦腈碱化合物的合成和其在不对 称催化反应中的应用研究进展. 手性膦腈碱的有机催化 在近几年来迅速发展, 无论是结构新颖的催化剂还是相 关反应类型都得到了不断的丰富, 所取得的研究成果大 多发表在化学权威期刊上, 引人注目. 然而, 膦腈碱催 化应用于天然产物的全合成的报道屈指可数, 而且在精 细化学品合成中的实际应用迄今为止也未见报道 ${ }^{[70]}$. 究其原因, 一方面是手性膦腈碱的难以制备限制了其应 用, 虽然本文所述的部分催化剂也有一些商品化的尝 试, 但是价格仍然极其昂贵; 另一方面可能是膦腈碱催 化剂对底物范围普适性和官能团耐受度的不足，阻碍了 其应用方面的尝试. 除此之外, 膦腈碱碱性的强弱与催 化活性存在一定的矛盾. 提高催化剂碱性可以活化惰性 反应底物，但致使催化剂容易猝灭而无法再生，因此不 能完成催化循环. 碱性与稳定性也互相抵触, 碱性太强 往往不太稳定从而限制了其应用. 因此, 合理设计膦腈 碱化合物的碱性，取得反应底物与催化剂之间的匹配至 关重要. 通过催化剂结构的修饰达成与反应类型的平衡 是实现膦腈有机超强碱催化普适性的关键. 基于此, 手 性膦腈碱催化化学会持续更新. 毫无疑问, 更多的科研 小组会进入该领域，一定会出现越来越多的研究成果， 最终实现手性膦腈碱催化的实际应用而造福社会.

\section{References}

[1] List, B.; Lerner, R. A.; Barbas, C. F. J. Am. Chem. Soc. 2000, 122 , 2395.

[2] Ahrendt, K. A.; Borths, C. J.; Macmillan, D. W. C. J. Am. Chem. Soc. 2000, 122, 4243.

[3] Bredig, G.; Fiske, P. S. Biochem. Z. 1912, 46, 7.

[4] Schwesinger, R. Chimia 1985, 39, 269

[5] Schwesinger, R.; Hasenfratz, C.; Schlemper, H.; Walz, L.; Peters, E.-M.; Peters, K.; Schnering, H. G. V. Angew. Chem., Int. Ed. 1993, $32,1361$.

[6] Schwesinger, R.; Schlemper, H. Angew. Chem., Int. Ed. 1987, 26, 1167.

[7] Schwesinger, R.; Schlemper, H.; Hasenfratz; C. Willaredt, J.; Dambacher, T.; Breuer, T.; Ottaway, C.; Fletschinger, M.; Boele, J.; Fritz, H.; Putzas, D.; Rotter, H. W.; Bordwell, F. G.; Satish, A. V.; Ji, G.-Z.; Peters, E.-M.; Peters, K.; Schnering, H. G. V.; Walz, L. Liebigs Ann. 1996, 1055.

[8] Koppel, I. A.; Schwesinger, R.; Breuer, T.; Burk, P.; Herodes, K.; Koppel, I.; Leito, I.; Mishima, M. J. Phys. Chem. A 2001, 105, 9575.

[9] Allen, C. W. Coord. Chem. Rev. 1994, 130, 137.

[10] Allen, C. W. Organophosphorus Chem. 1996, 27, 308.

[11] Kondo, Y.; Ueno, M.; Tanaka, Y. J. Synth. Org. Chem., Jpn. 2005, $63,453$.

[12] Ishikawa, T. Superbases for Organic Synthesis: Guanidines, Amidines, Phosphazenes and Related Organocatalysts, John Wiley \& Sons, Chichester, West Sussex, 2009, p. 6.

[13] Köhn, U.; Schulz, M.; Schramm, A.; Günther, W.; Görls, H.; Schenk, S.; Anders. E. Eur. J. Org. Chem. 2006, 4128.

[14] Naka, H.; Kanase, N.; Ueno, M.; Kondo, Y. Chem.-Eur. J. 2008, 14, 5267.
[15] Kögel, J. F.; Kneusels, N.-J.; Sundermeyer, J. Chem. Commun. 2014, 50, 4319.

[16] Uraguchi, D.; Sakaki, S.; Ooi, T. J. Am. Chem. Soc. 2007, 129, 12392.

[17] Simón, L.; Paton, R. S. J. Org. Chem. 2015, 80, 2756.

[18] Uraguchi, D.; Ito, T.; Nakamura, S.; Sakaki, S.; Ooi, T. Chem. Lett. 2009, 38, 1052 .

[19] Uraguchi, D.; Nakamura, S.; Ooi, T. Angew. Chem., Int. Ed. 2010 , $49,7562$.

[20] Uraguchi, D.; Ito, T.; Ooi, T. J. Am. Chem. Soc. 2009, 131, 3836.

[21] Uraguchi, D.; Ito, T.; Kimura, Y.; Nobori, Y.; Sato, M.; Ooi, T. Bull. Chem. Soc. Jpn. 2017, 90, 546.

[22] Uraguchi, D.; Ito, T.; Nakamura, S.; Ooi, T. Chem. Sci. 2010, 1, 488.

[23] Corbett, M. T.; Uraguchi, D.; Ooi, T.; Johnson, J. S. Angew. Chem., Int. Ed. 2012, 51, 4685.

[24] Uraguchi, D.; Ueki, Y.; Ooi, T. Chem. Sci. 2012, 3, 842.

[25] Uraguchi, D.; Ueki, Y.; Ooi, T. Science 2009, 326, 120.

[26] Uraguchi, D.; Ueki, Y.; Ooi, T. Angew. Chem., Int. Ed. 2011, 50, 3681.

[27] Uraguchi, D.; Ueki, Y.; Ooi, T. J. Am. Chem. Soc. 2008, 130 14088

[28] Uraguchi, D.; Yoshioka, K.; Ueki, Y.; Ooi, T. J. Am. Chem. Soc. 2012, 134, 19370 .

[29] Uraguchi, D.; Yoshioka, K.; Ooi, T. Nat. Commun. 2017, 8, 14793.

[30] Yamanaka, M.; Sakata, K.; Yoshioka, K.; Uraguchi, D.; Ooi, T. J. Org. Chem. 2017, 82, 541

[31] Yoshioka, K.; Yamada, K.; Uraguchi, D.; Ooi, T. Chem. Commun. 2017, 53, 5495.

[32] Uraguchi, D.; Ueki, Y.; Sugiyama, A.; Ooi, T. Chem. Sci. 2013, 4 , 1308.

[33] Simón, L.; Paton, R. S. J. Org. Chem. 2017, 82, 3855.

[34] Uraguchi, D.; Shibazaki, R.; Tanaka, N.; Yamada, K.; Yoshioka, K.; Ooi, T. Angew. Chem., Int. Ed. 2018, 57, 4732.

[35] Uraguchi, D.; Yamada, K.; Ooi, T. Angew. Chem., Int. Ed. 2015, 54, 9954.

[36] Uraguchi, D.; Nakamura, S.; Sasaki, H.; Konakade, Y.; Ooi, T. Chem. Commun. 2014, 50, 3491.

[37] Uraguchi, D.; Kawai, Y.; Sasaki, H.; Yamada, K.; Ooi, T. Chem. Lett. 2018, 47, 594.

[38] (a) Uraguchi, D.; Tsutsumi, R.; Ooi, T. J. Am. Chem. Soc. 2013, 135,8161 .

(b) Uraguchi, D.; Tsutsumi, R.; Ooi, T. Tetrahedron 2014, 70, 1691. (c) Tsutsumi, R.; Kim, S.; Uraguchi, D.; Ooi, T. Synthesis 2014, 46, 871.

[39] Tanaka, N.; Tsutsumi, R.; Uraguchi, D.; Ooi, T. Chem. Commun. 2017, 53, 6999 .

[40] Horwitz, M. A.; Tanaka, N.; Yokosaka, T.; Uraguchi, D.; Johnson, J. S.; Ooi, T. Chem. Sci. 2015, 6, 6086.

[41] Uraguchi, D.; Yamada, K.; Sato, M.; Ooi, T. J. Am. Chem. Soc. 2018, 140,5110

[42] Uraguchi, D.; Nakashima, D.; Ooi, T. J. Am. Chem. Soc. 2009, 131, 7242.

[43] Uraguchi, D.; Kinoshita, N.; Nakashima, D.; Ooi, T. Chem. Sci. 2012, 3, 3161.

[44] Uraguchi, D.; Kinoshita, N.; Kizu, T.; Ooi, T. J. Am. Chem. Soc. 2015, 137, 13768 .

[45] Kizu, T.; Uraguchi, D.; Ooi, T. J. Org. Chem. 2016, 81, 6953.

[46] Uraguchi, D.; Asai, Y.; Ooi, T. Angew. Chem., Int. Ed. 2009, 48, 733.

[47] Takeda, T.; Terada, M. J. Am. Chem. Soc. 2013, 135, 15306

[48] Hu, Q.; Kondoh, A.; Terada, M. Chem. Sci. 2018, 9, 4348.

[49] Kondoh, A.; Oishi, M.; Takeda, T.; Terada, M. Angew. Chem., Int. Ed. 2015, 54, 15836 .

[50] Takeda, T.; Kondoh, A.; Terada, M. Angew. Chem., Int. Ed. 2016, $55,4734$.

[51] Kondoh, A.; Akahira, S.; Oishi, M.; Terada, M. Angew. Chem., Int. Ed. 2018, 57, 6299. 
[52] Gao, X.; Han, J.; Wang, L. Org. Lett. 2015, 17, 4596.

[53] Gao, X.; Han, J.; Wang, L. Org. Chem. Front. 2016, 3, 656.

[54] Zhang, Y.; Wu, X.-Y.; Han, J.; Wong, H. N. C. Tetrahedron Lett. 2020, 61, 151559 .

[55] Li, B.; Xu, Z.-J.; Han, J. Tetrahedron Lett. 2018, 59, 2412.

[56] Gao, X.; Han, J.; Wang, L. Synthesis 2016, 48, 2603.

[57] Han, J.; Zhang, Y.; Wu, X.-Y.; Wong, H. N. C. Chem. Commun. 2019, 55, 397.

[58] Zhang, Y.; Wong, H. N. C.; Wu, X.-Y.; Han, J. Tetrahedron Lett. 2020, 61, 151755

[59] Zhang, Y.; Wu, X.-Y.; Han, J. Chin. Chem. Lett. 2019, 30, 1519.

[60] Núñez, M. G.; Farley, A. J. M.; Dixon, D. J. J. Am. Chem. Soc. 2013, 135, 16348.

[61] Goldys, A. M.; Núñez, M. G.; Dixon, D. J. Org. Lett. 2014, 16, 6294.
[62] Robertson, G. P.; Farley, A. J. M.; Dixon, D. J. Synlett 2016, 27, 21.

[63] Horwitz, M. A.; Zavesky, B. P.; Martinez-Alvarado, J. I.; Johnson, J. S. Org. Lett. 2016, 18, 36.

[64] Horwitz, M. A.; Fulton, J. L.; Johnson, J. S. Org. Lett. 2017, 19, 5783.

[65] Farley, A. J. M.; Sandford, C.; Dixon, D. J. J. Am. Chem. Soc. 2015, 137, 15992.

[66] Yang, J.; Farley, A. J. M.; Dixon, D. J. Chem. Sci. 2017, 8, 606.

[67] Formica, M.; Sorin, G.; Farley, A. J. M.; Díaz, J.; Paton, R. S.; Dixon, D. J. Chem. Sci. 2018, 9, 6969.

[68] Thomson, C. J.; Barber, D. M.; Dixon, D. J. Angew. Chem., Int. Ed. 2020, $59,5359$.

[69] Kondoh, A.; Oishi, M.; Tezuka, H.; Terada, M. Angew. Chem., Int. Ed. 2020, 59, 7472 .

[70] Enders, D.; Nguyen, T. V. Org. Biomol. Chem. 2012, 10, 5327.

(Zhao, C.) 